\title{
Neuregulin-1 Promotes Myocardial Angiogenesis in the Rat Model of Diabetic Cardiomyopathy
}

\author{
Chun Gui $^{a}$ Zhi-yu Zeng ${ }^{a} \quad$ Qi Chen $^{b} \quad$ Ya-wei Luo ${ }^{c} \quad$ Lang Li $^{a} \quad$ Lin-lin Chen ${ }^{a}$ \\ a Department of Cardiology, The First Affiliated Hospital, Guangxi Medical University, Nanning, Guangxi, \\ China; ${ }^{b}$ Electrophysiology Research Laboratory, Texas Heart Institute/CHI St. Luke Hospital, Houston, \\ USA, 'Department of Cardiology, Beijing Anzhen Hospital, Capital Medical University, Beijing, China
}

\section{Key Words}

Diabetic cardiomyopathy $•$ Neuregulin-1 1 Angiogenesis $•$ VEGF $•$ Angiopoietin-1

\begin{abstract}
Background/Aims: Microvascular insufficiency takes a critical role in the development of diabetic cardiomyopathy (DCM). So this study was designed to investigate the effects of Neuregulin-1 (NRG-1) treatment on myocardial angiogenesis and the changes of VEGF/Flk1 and Ang-1/Tie-2 signaling in the rat model of DCM. Methods: Diabetic rats were induced by a single intraperitoneal injection of Streptozotocin. 12 weeks after the diabetes induction, the rats with NRG-1 treatment were treated with tail vein injection of NRG-1 at the dose of $10 \mu \mathrm{g} / \mathrm{kg} / \mathrm{d}$ for consecutive 10 days. Cardiac function was assessed using catheter MPA cardiac function analysis system. Myocardial blood flow (MBF) was assessed with stable-isotope labeled microspheres. Capillary density was measured by CD31 immunohistochemistry. The protein expression and receptors phosphorylation were assessed using western blot. Results: Left ventricular function, capillary density and MBF were significantly reduced in DCM group when compared with those in the control group $(P<0.01, P<0.01$ and $P<0.05$ respectively). Left ventricular function and capillary density were significantly increased in NRG-1 treatment group when compared with those in the DCM group $(P<0.05$ and $P<0.05$ respectively). The expression of VEGF and Ang-1 and the phosphorylation of Flk1 and Tie-1 were significantly decreased in DCM group as compared with those in the control group. However, those in the NRG-1 treatment group were significantly increased as compared with those in the DCM group. In vitro, NRG-1 treatment increased significantly the expression of VEGF and Ang-1 in human coronary artery smooth muscle cells. Conclusions: NRG-1 can increase the myocardial angiogenesis of DCM, probably via the direct effects of NRG-1 and via the increasing expression of VEGF and Ang-1. These findings may contribute to developing a novel approach to reverse the impaired angiogenic responses in diabetes or coronary artery disease.
\end{abstract}




\section{Introduction}

Diabetes is one of the most important risk factors for developing cardiovascular disease. Diabetes may result in diabetic cardiomyopathy (DCM), which is defined as myocardial dysfunction in the absence of coronary artery disease or systemic hypertension [1]. Microvascular insufficiency takes a critical role in the development of DCM. Accumulating evidences have demonstrated a progressive reduction of the microvasculature and an impaired angiogenic response to chronic ischemia with the development of diabetes [2,3]. These microvascular changes may lead to reduced perfusion of myocardium and contribute to adverse cardiovascular events [4]. Previous studies have reported the possible role of decreased vascular endothelial growth factor (VEGF) and angiopoietin-1 (Ang-1) in the pathogenesis of diabetes mediated impairment of myocardial angiogenesis [5, 6].

Neuregulin-1 (NRG-1) is a member of the epidermal growth factor family. NRG-1 receptors are the ErbB family of tyrosine kinase transmembrane receptors, including the ErbB2, ErbB3 and ErbB4. In the heart, NRG-1 is synthesized and released by the endocardial and cardiac microvascular endothelium [7]. NRG-1 is essential for the development of the cardiovascular system and the maintenance of adult heart function [8]. Recently, growing evidences indicated that NRG-1 was a positive regulator of angiogenesis. Russell et al. reported NRG-1 and ErbB receptors are expressed in vascular endothelial cells, and angiogenesis could be induced by the stimulation of endothelial cells in vitro [9]. Hedhli et al. reported that NRG-1 of endothelial production is necessary for angiogenesis and arteriogenesis induced by femoral artery ligation, and exogenous administration of NRG-1 can enhance this process [10].

Our previous study showed NRG-1 protein expression and the phosphorylation of ErbB receptors are impaired in DCM [11]. The another study of us showed serum NRG-1 $\beta$ levels were positively correlated with serum VEGF and Ang-1 levels in patients with diabetes [12]. So there may be some relations between NRG-1 and angiogenic factors. However, it is not clear whether the reinforced NRG-1/ErbB signaling can increase the expression of angiogenic factors and angiogenesis in the myocardium of DCM. Therefore, the aim of this study was to investigate the effects of NRG-1 treatment on myocardial angiogenesis and the changes of VEGF/FLK1 and Ang-1/Tie-2 signal conduction in a rat model of DCM.

\section{Materials and Methods}

\section{Experimental materials}

Streptozotocin (STZ) and p-Tie-2 antibody were obtained from Sigma chemical company (USA); VEGF, CD31 and GAPDH antibodies were obtained from Santa Cruz Biotechnology (USA); Ang-1 antibodies was obtained from Proteintech group (USA); p-VEGF Receptor 2 (p-Flk1)antibody was obtained from Abcam (USA); Stable-isotope labeled microspheres was obtained from BioPAL company (USA); human coronary artery smooth muscle cells (HCASMCs) was obtained from Lifeline cell technology (USA); recombinant human NRG-1, Tyrphostin AG1478, ErbB receptors and phosphorylation of ErbB receptors antibodies were obtained from Cell Signaling Technology (USA).

\section{Induction of diabetes}

All animal experiments were approved by the Animal Care and Use Committee of the Guangxi Medical Institute and complied with the "Guide for the Care and Use of Laboratory Animals", which was published by the US National Institute of Health (8th edition, 2011). Male Sprague-Dawley rats of 7-8 weeks old and of 160-180g weight were obtained from the Animal Center of Guangxi Medical University. Rats were randomly separated into normal control and diabetic rats. Diabetes was induced as previously described [5, 13] by a single intraperitoneal injection of STZ $(55 \mathrm{mg} / \mathrm{kg}$ in $0.1 \mathrm{~mol} / \mathrm{L}$ citrate buffer, $\mathrm{pH} 4.5)$. The control rats were injected with the same volume of $0.1 \mathrm{~mol} / \mathrm{L}$ citrate buffer. Tail blood glucose was measured every week during experiments, and all diabetic rats with blood glucose levels $<16.7 \mathrm{mmol} / \mathrm{L}$ were excluded from further study. The experiment rats were divided into three groups, including control group (n=10), DCM 


\section{Cellular Physiology Cell Physiol Biochem 2018;46:2325-2334 \\ \begin{tabular}{l|l} 
and Biochemistry Published online:1May 09, 2018 & $\begin{array}{l}\text { Do } 2018 \text { The Author(s). Published by S. Karger AG, Basel } \\
\text { www.karger.com/cpb }\end{array}$ \\
\hline
\end{tabular}}

Gui et al.: NRG-1 Promotes Myocardial Angiogenesis in DCM

group $(n=10)$ and NRG-1 treatment group $(n=10) .12$ weeks after the diabetes induction, diabetic rats were randomly separated into DCM group and NRG-1 treatment group. The rats in NRG-1 treatment group were treated with tail vein injection of NRG-1 at the dose of $10 \mu \mathrm{g} / \mathrm{kg} / \mathrm{d}$ for consecutive 10 days and the rats in DCM group were given $0.1 \mathrm{mmol} / \mathrm{L}$ citrate buffer injection.

\section{Assessment of cardiac function}

Cardiac function was assessed through $\mathrm{dp} / \mathrm{dt}$ values as described in previous studies $[3,5]$. Ten days after NRG-1 treatment, at time of tissue harvest, anesthesia was performed with $10 \%$ chloralhydrate $(0.3-$ $0.4 \mathrm{ml} / 100 \mathrm{~g}$ ) by the intraperitoneal injection in all rats. The rats were intubated and mechanically ventilated at $4 \mathrm{ml} / 100 \mathrm{~g}$ of tidal volume. A small left anterolateral longitudinal thoracotomy was performed following skin preparation. The apex was exposed and a left ventricular catheter was surgically inserted from the apex directly into the left ventricle. And then cardiac function was assessed by using catheter MPA cardiac function analysis system, and the left ventricular maximum $+\mathrm{dp} / \mathrm{dt}$ (systolic function) and minimum - dp/ $\mathrm{dt}$ (diastolic function) were recorded.

\section{Assessment of myocardial blood flow}

Myocardial blood flow (MBF) was assessed by using the stable-isotope labeled microspheres as described in previous studies [3,14]. A left femoral artery catheter was inserted to the level of the renal artery for arterial blood collection. Gold-labeled microspheres of $15 \mu \mathrm{m}$ in diameter were injected into the left atrium with a dose of $0.6 \mathrm{ml}$. The rats were then humanely killed by intracardiac injection of a saturated $\mathrm{KCl}$ solution $(10 \mathrm{ml} / \mathrm{kg})$. Transmural left ventricular sections of $50 \mathrm{mg}$ were harvested for myocardial microspheres analyses in each rat. Myocardial samples were weighed and placed into a BioPAL sample vial, and were dried at $70^{\circ} \mathrm{C}$ for 24 hours. Blood samples were transferred to a BioPAL blood sample vial, then centrifuged and discarded supernatant. All tissue and blood samples were sent to BioPhysics Assay Laboratory for myocardial blood flow measurements.

\section{Capillary density measurements}

Capillary density was measured by CD31 immunohistochemistry. Tissues were collected from the left ventricle and fixed in $4 \%$ paraformaldehyde. Myocardial cross sections ( $5 \mu \mathrm{m}$ ) were prepared by conventional dewaxing hydration procedures and $3 \%$ hydrogen peroxide $(50 \mu \mathrm{l})$ was added to each slice. The samples were incubated at room temperature, and then CD31 primary antibody (50 $\mu \mathrm{l})$ was added. After 2-3 hours, real time MaxVision $(50 \mu \mathrm{l})$ was added for incubation. Myocardial sections were stained with DAB solution, and counterstained with hematoxylin. Capillary density was assessed by capillaries/myocyte nucleus (C/M) values. $\mathrm{C} / \mathrm{M}$ values were counted in 5 fields randomly selected from each slice by two blinded observers.

\section{HCASMCs culture}

The primary HCASMCs from liquid nitrogen were completely dissolved in $37^{\circ} \mathrm{C}$ water bath and cultured in a $37^{\circ} \mathrm{C}$ and $5 \% \mathrm{CO}_{2}$ incubator. The medium was changed every 3days. At confluence the cells were passaged. In all experiments, the cells of the 3th passages were used. Tyrphostin AG1478 (ErbB inhibitor, $10 \mathrm{uM}$ ) and NRG-1 (50ng/ml) were added for 24 hours according to the need of tests. In model of hypoxia and serum deprivation (hypo/SD), the cells were incubated in a modular incubator chamber and infused with mixed gas $\left(95 \% \mathrm{~N}_{2}\right.$ and $\left.5 \% \mathrm{CO}_{2}\right)$ at $37^{\circ} \mathrm{C}$ and $\mathrm{O}_{2}<0.5 \%$ for 24 hours. The experiment cells were divided into 4 groups, including control group, hypo/SD group, NRG-1 treatment group (hypo/SD+NRG-1) and AG1478 group (hypo/SD+NRG-1+AG1478).

\section{Western blot analysis}

The frozen myocardial tissues of left ventricle was crushed with a mortar and pestle at the temperature of liquid nitrogen and placed into $1.5 \mathrm{ml}$ micro-tubes. RIPA buffer was added to the micro-tubes immediately prior to the tissue lysis, and then protein extraction and quantification were performed. Total protein was fractionated by gel electrophoresis and transferred to the membrane. The membranes were blocked with $5 \%$ nonfat milk for $1 \mathrm{~h}$ at room temperature followed by overnight incubation at $4{ }^{\circ} \mathrm{C}$ with primary antibodies. Primary antibody binding was detected using a horseradish peroxidase conjugated secondary antibody and an enhanced chemiluminescence detection system. The bands were analyzed using Image-Pro Plus6.0 software. 
Statistical analysis

The numerical values were expressed as the Mean \pm SD. The data were analyzed using the SPSS 16.0 statistic software package. Student's t-test was used to compare the two groups, and One-way analysis of variance was performed, and post hoc multiple comparisons were conducted with S-N-K. Statistical significance was defined as $\mathrm{P}<0.05$.

\section{Results}

\section{Rat model of DCM}

Within 2 days of injection, STZ provoked a prominent hyperglycemia accompanied by typical symptoms of diabetes. Blood glucose was measured each week throughout the study, and the results were showed in Table1. All diabetic rats with blood glucose levels less than $16.7 \mathrm{mmol} / \mathrm{L}$ were excluded from further study. Finally, there were 10 rats each group for further study. Diabetic rats demonstrated significant cachexia, decreased body weight gain and increased food and water intake.

To confirm the effectivity of recombinant human NRG1 injection on myocardium of rats, we examined the phosphorylation of ErbB receptors after NRG-1 injection. The results showed the phosphorylation of ErbB2 and ErbB3 were significantly decreased in the diabetic rats, but were significantly increased after NRG-1 treatment, which suggested that recombinant human NRG-1 through tail vein injection is viable in diabetic rats (Fig. 3).
Table 1. Random blood glucose lever in the three groups (mmol/L)

\begin{tabular}{lcccc}
\hline & Control $(\mathrm{n}=10)$ & DCM $(\mathrm{n}=10)$ & NRG-1 $(\mathrm{n}=10)$ & P values \\
\hline 0 day & $7.48 \pm 1.28$ & $7.28 \pm 0.65$ & $7.55 \pm 0.78$ & 0.080 \\
1 week & $7.01 \pm 0.71$ & $25.43 \pm 4.41$ & $25.55 \pm 3.82$ & 0.000 \\
4 weeks & $6.89 \pm 1.71$ & $29.08 \pm 2.25$ & $28.4 \pm 2.17$ & 0.000 \\
8 weeks & $6.87 \pm 0.76$ & $28.36 \pm 2.98$ & $27.95 \pm 2.49$ & 0.000 \\
12 weeks & $7.13 \pm 1.03$ & $26.37 \pm 4.42$ & $25.98 \pm 3.52$ & 0.000 \\
13 weeks & $7.40 \pm 0.63$ & $25.82 \pm 3.64$ & $24.99 \pm 3.08$ & 0.000 \\
\hline
\end{tabular}

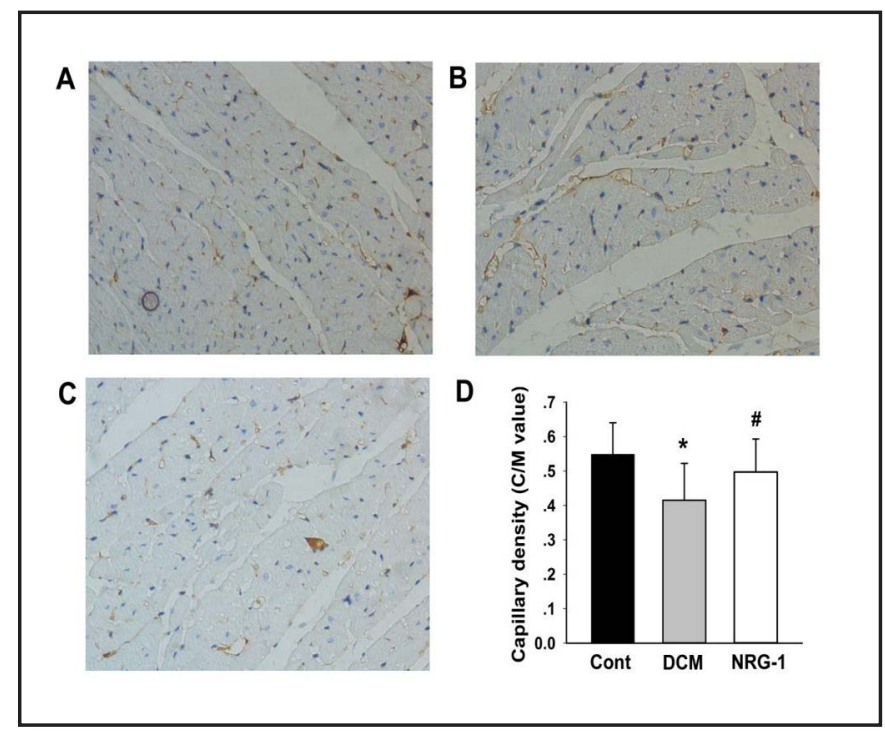

Fig. 1. Effect of NRG-1 on capillary density in DCM. A: CD31 staining in Control group; B: CD31 staining in DCM group; C: CD31 staining in NRG-1 treatment group; D: The comparison of C/M values among three groups. The magnification of light microscope is 100 . The brown staining indicates the CD31+ capillary endothelial cells. Myocardial sections were counterstained with hematoxylin (the blue nucleus staining). *: $\mathrm{P}<0.01$ versus control group; \#: $\mathrm{P}<0.05$ versus DCM group.

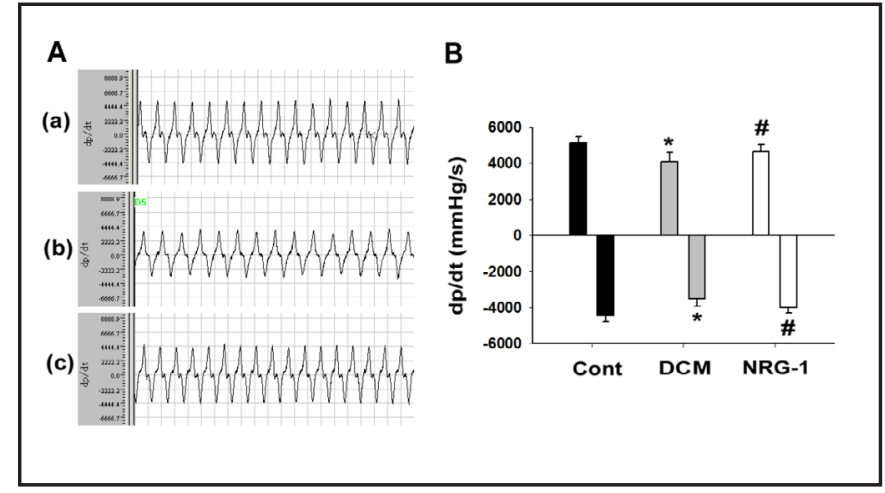

Fig. 2. Left ventricular $+d p / d t$ and $-d p / d t$ values in three groups. A: The diagrams of dp/dt in control group(a), DCM group(b) and NRG-1 group(c); B: The comparison of $+d p / d t$ and -dp/dt among three groups. *: $\mathrm{P}<0.01$ versus control group; \#: $\mathrm{P}<0.05$ versus DCM group. 
Cardiac function

The results of cardiac function test showed both $+\mathrm{dp} / \mathrm{dt}$ and $-\mathrm{dp} / \mathrm{dt}$ values were significantly lower in DCM group than that in control group [(4094 \pm 503.95$) \mathrm{mmHg} / \mathrm{s}$ vs. $(5102.4 \pm 373.34) \mathrm{mmHg} / \mathrm{s}$, $\mathrm{P}<0.01 ;(3535.7 \pm 415.62)$ $\mathrm{mmHg} / \mathrm{s}$ $v s$. $(4448.9 \pm 347.49) \mathrm{mmHg} / \mathrm{s}$, $\mathrm{P}<0.01]$. But both $+\mathrm{dp} /$ $\mathrm{dt}$ and $-\mathrm{dp} / \mathrm{dt}$ values were significantly improved in NRG-1 treatment group than that in DCM group [(4615.4 \pm 407.9$)$ $\mathrm{mmHg} / \mathrm{s}$ vs. (4094 \pm 503.95$)$ $\mathrm{mmHg} / \mathrm{s}, \quad \mathrm{P}<0.05$; $(4012.0 \pm 282.75) \mathrm{mmHg} / \mathrm{s}$ vs. $\quad(3535.7 \pm 415.62)$ $\mathrm{mmHg} / \mathrm{s}, P<0.05$ ] (Fig. 2).

\section{Capillary density}

Capillary density was evaluated by CD31 staining and quantified by capillaries/myocyte nucleus (C/M) values. Capillary density was significantly reduced in DCM group when compared with that in the control group $(0.415 \pm 0.107$ vs. $0.548 \pm 0.092, P<0.01)$. Capillary density was significantly increased in NRG1 treatment group when compared with that in the DCM group $(0.497 \pm 0.096$ vs. $0.415 \pm 0.107, P<0.05)$. It indicated that NRG-1 treatment can improve capillary density in DCM (Fig. 1).

\section{Local MBF}

The stable-isotope labeled microspheres were used to determine MBF. Rats in DCM group demonstrated reduced MBF as compared to the rats in control group [(3.38 \pm 1.17$)$ $\mathrm{ml} / \mathrm{g} / \mathrm{min}$ vs. $(3.94 \pm 1.02) \mathrm{ml} / \mathrm{g} / \mathrm{min}, P<0.05]$. The MBF in the NRG-1 treatment group was increased but did not reach significantly difference when compared with that in the DCM group [(3.78 \pm 1.25$) \mathrm{ml} / \mathrm{g} / \mathrm{min} v s .(3.38 \pm 1.17) \mathrm{ml} / \mathrm{g} / \mathrm{min}, \quad P>0.05]$.

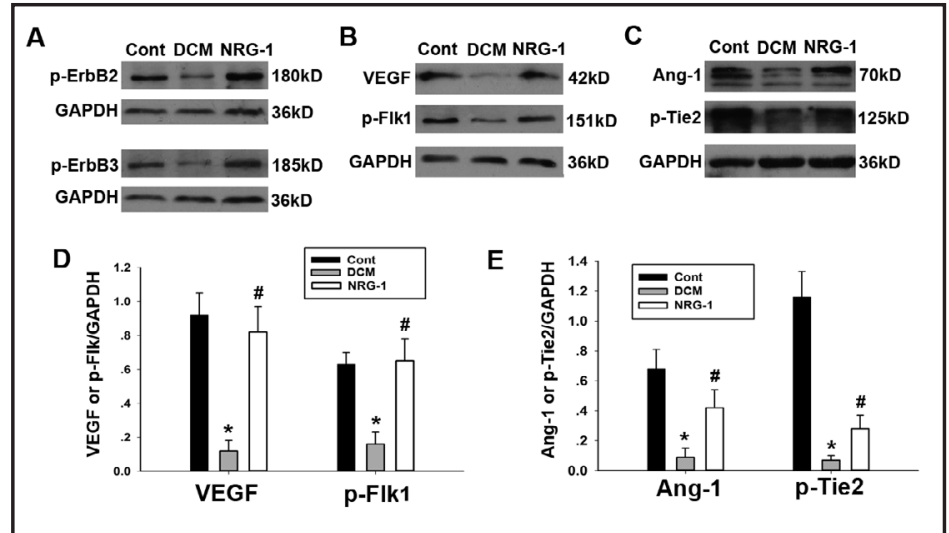

Fig. 3. Left ventricular VEGF/Flk1 and Ang-1/Tie-2 systems were examined in the different groups. A: The phosphorylation of ErbB2 and ErbB3; B: VEGF expression and Flk1 phosphorylation; C: Ang-1 expression and Tie-2 phosphorylation; D: The comparison of VEGF expression and Flk1 phosphorylation among three groups; E: The comparison of Ang-1 expression and Tie-2 phosphorylation among three groups; *: $\mathrm{P}<0.01$ versus control group; \#: $\mathrm{P}<0.01$ versus DCM group.

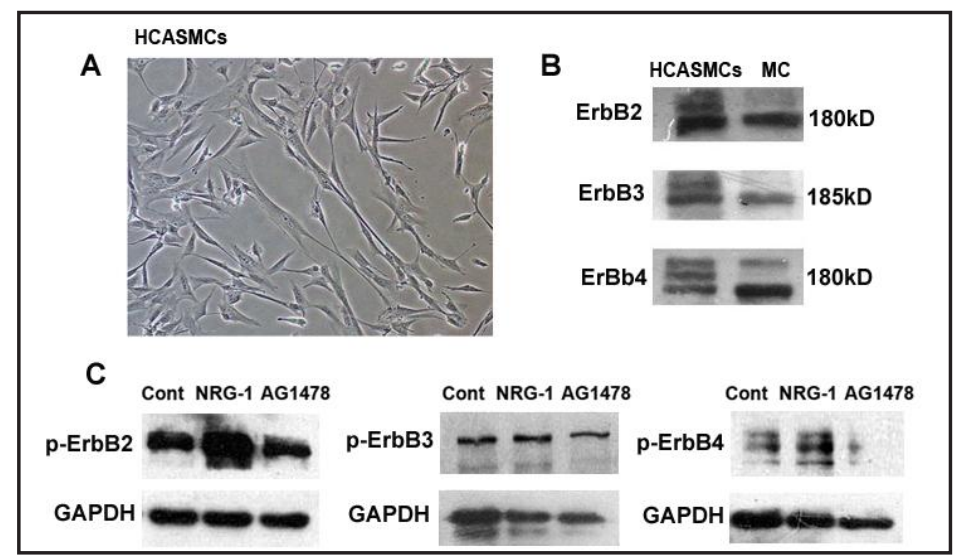

Fig. 4. ErbB receptors were expressed and their phosphorylation were induced by NRG-1 treatment in HCASMCs. A: the shape of HCASMCs under a phase contrast microscope (original magnification $\times 100$ ); B: ErbB2, ErbB3 and ErbB4 were expressed in HCASMCs, MC (Myocardium) as a positive contrast; C: NRG-1 significantly induced the phosphorylation of ErbB2 and ErbB4. 
VEGF/Flk1 and Ang-1/

Tie-2 signaling

To investigate whether angiogenic factors are associated with myocardial angiogenesis induced by NRG-1 treatment, we examined the VEGF/Flk1 and Ang-1/Tie-2 signaling systems using western blot analysis. Compared with the control group, rats in DCM group demonstrated a significant reduction in VEGF expression and Flk1 phosphorylation. However, in the NRG-1 treatment group, VEGF expression and Flk-1 phosphorylation were significantly increased as compared with that in the DCM group (Fig. 3).

Similarly, Ang-1 expression in the diabetic heart was significantly decreased, which was accompanied by a dramatic decrease in Tie- 2 phosphorylation as compared with that in the control group. However, Ang-1 expression and Tie-2 phosphorylation in the NRG-1 treatment group were significantly increased as compared with that in the DCM group (Fig. 3).

The expression of VEGF and Ang-1 in HCASMCS

Vessels mainly consist of endothelial cells and smooth muscle cells (SMCs). Both VEGF and Ang-1 are expressed in SMCs, but their receptors Flk1 and Tie-2 are expressed almost exclusively in endothelial cells. By paracrine regulation, VEGF and Ang-1 can promote angiogenesis including new vessels formation and maturation. So we further examined the effects of NRG-1 treatment on the expression of VEGF and Ang-1 in HCASMCs under hypo/ SD conditions, which are both components of ischemia in vivo.

Firstly, we confirmed that ErbB2, ErbB3 and ErbB4 receptors were expressed in HCASMCs by western blot. NRG-1 treatment significantly induced the phosphorylation of ErbB receptors which were inhibited by AG1478. These results suggested NRG-1 played some roles in HCASMCs by signal transduction (Fig. 4).

Secondly, we examined whether NRG-1 could induce the expression of VEGF and Ang-1 in HCASMCs. The results showed hypo/SD stimulation significantly increased the expression of VEGF and Ang-1 in HCASMCs, and NRG-1 treatment further significantly increased their expression. But when cells were added with AG1478 simultaneously, the increased expression of VEGF and Ang-1 induced by NRG-1 disappeared (Fig. 5).

\section{Discussion}

This study for the first time reported the effects of NRG-1 on myocardial angiogenesis in DCM. The results showed NRG-1 could improve the left ventricular function and capillary density in DCM, and there was a trend toward higher local MBF in diabetic rats with NRG-1 treatment although not reaching statistical difference. This study also showed NRG-1 could 


\section{Cellular Physiology Cell Physiol Biochem 2018;46:2325-2334

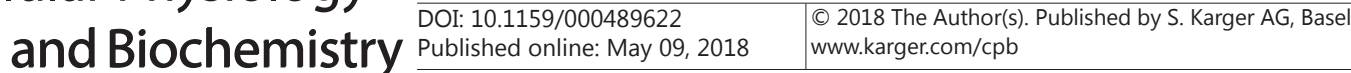

Gui et al.: NRG-1 Promotes Myocardial Angiogenesis in DCM

increase the myocardial expression of VEGF and Ang-1 and the phosphorylation of Flk1 and Tie-2. In vitro, NRG-1 treatment could increase the expression of VEGF and Ang-1 in HCASMCs.

The rat model of DCM in this study has been used in the previous study [5]. Our previous study showed the cardiac function was already impaired 3 months after induction of diabetes [11]. In diabetes, many factors affect cardiac systolic and diastolic function. These factors include metabolic disturbances, myocardial fibrosis, small vessel disease and cardiac autonomic neuropathy. This study showed cardiac function was significantly improved in diabetic rats with NRG-1 injection. NRG-1 is synthesized and released by the endocardial and cardiac microvascular endothelium, while ErbB2 and ErbB4 are expressed in cardiomyocytes. The NRG-1/ErbB system is necessary for physiological adaptation of the heart to the changes of cardiac demand, and disruption of this system impairs recovery of cardiac contractile function [15]. Odiete et al. reported diabetes can prevent compensatory up-regulation of myocardial NRG-1/ErbB after myocardial infarction coincident with an increased severity of heart failure [16]. Previous studies also reported NRG-1 can improve cardiac function in animal models of heart disease including ischemic, dilated, and viral cardiomyopathy $[17,18]$. NRG-1 can promote the growth and survival of cardiomyocytes [19], modulate myofibrillar disarray [20], maintain mitochondrial function and integrity [21], stimulate glucose uptake [22] and increase sarcoplasmic reticulum calcium uptake [23]. These effects of NRG-1 contribute to the beneficial effects of NRG-1 on cardiac function. In this study, increased angiogenesis may also improve the cardiac function of diabetic rats.

The decrease of capillary density and MBF were found in diabetic rats in our study, which were associated with the decreased expression of VEGF and Ang-1 and phosphorylation of Flk-1 and Tie-2. These results are consistent with the findings of previous studies [3-6]. Cardiac remodeling induced by diabetes is associated with microvascular pathologies, which include reduced expression of angiogenic factors, decreased endothelial cell infiltration, increased endothelial cell apoptosis [24], decreased circulating endothelial precursor cells (EPCs) and impaired EPCs function [25, 26].

In this study, diabetic rats with NRG-1 injection demonstrated increased capillary density. Russell et al. reported that NRG-1 is proangiogenic in vitro using a collagen gel cord formation assay, and in vivo in a rat corneal angiogenesis assay [9]. Another study showed endothelial-specific NRG-1 deletion results in a significant decrease in vascular growth induced by ischemia, and addition of exogenous NRG-1 can accelerate blood flow recovery after femoral artery ligation [10]. Both NRG-1 and ErbB receptors are expressed in vascular endothelial cells, and deletion of NRG-1 significantly impaired endothelial cord formation, which indicates that this system may participate in an autocrine angiogenic response. NRG-1 induces an angiogenic response independent of VEGF [9], or via the increasing expression of VEGF [27]. ErbB receptors are expressed in EPCs, and NRG-1 stimulation can enhance EPCs survival and their participation in angiogenic responses [28]. Lok et al. reported that NRG-1 can decrease human brain endothelial cells death after oxidative injury with $\mathrm{H}_{2} \mathrm{O}_{2}$ [29]. Oxidative stress caused by mitochondrial superoxide overproduction in endothelial cells is the major mechanism in the development of vascular complications in diabetes [30, 31]. Previous study reported that NRG-1 can alleviate oxidative and endoplasmic reticulum stress in heart [32]. This study found MBF was increased in rats with NRG-1 treatment, but which didn't reach statistical difference. Some studies also reported the activation of ErbB3 and ErbB4 have been implicated in the recruitment of SMCs necessary for angiogenesis [33, 34]. But the process of vessel maturation includes a step by step transition from actively growing vessel bed to the quiescent fully formed and functional network.

Angiogenesis is mainly regulated by the interplay between VEGF and Ang-1. Both Flk1 and Tie-2 receptors are exclusively expressed in endothelial cells. VEGF/Flk1 signal system takes the lead in the process of new vessel formation, whereas Ang-1/Tie-2 signal system plays a critical role in vascular maturation and stabilization [35]. This study for the first time showed NRG-1 treatment can increase the expression of VEGF and Ang-1 and the phosphorylation of their receptors in DCM, and can also increase the expression of VEGF 
and Ang-1 in HCASMCs. It has been reported that NRG-1 can induce the expression of angiogenic factors in other tissues or cells. Bagheri et al. reported that NRG-1 can increase VEGF production in tumor cells [27]. Iivanainen et al. reported that NRG-1 can induce the secretion of VEGF in endothelial cells [36]. Nakaoka et al. found that NRG-1 stimulation can increase the mRNA expression of Ang-1 in the heart [37]. This study showed all three ErbB receptors are expressed in HCASMCs. So the interplay between endothelial cell and SMCs via NRG-1/ErbB signaling probably is an important potential mechanism for regulation of angiogenesis.

In terms of study limitations, our model of STZ-induced diabetes largely mimics type I diabetes, this model does not precisely represent the type II diabetes in humans. Although various pathophysiologic and molecular aspects are common between type I and type II diabetes, some features may be different and may limit the generalizability of this model to type II diabetes and insulin resistance.

In summary, NRG-1 can increase the myocardial angiogenesis of DCM, probably via the direct effects of NRG-1 and via the increasing expression of VEGF and Ang-1. Diabetes results in a profound impairment in the myocardial angiogenic responses to chronic ischemia. So these findings may contribute to developing a novel approach to reverse the impaired angiogenic responses in diabetes or coronary artery disease.

\section{Abbreviations}

DCM (diabetic cardiomyopathy); NRG-1 (Neuregulin-1); MBF (myocardial blood flow); VEGF (vascular endothelial growth factor); Ang-1 (angiopoietin-1); STZ (streptozotocin); HCASMCs (human coronary artery smooth muscle cells); hypo/SD (hypoxia and serum deprivation).

\section{Acknowledgements}

This study was supported by National Natural Science Foundation of China

(No.81160021 and No.81460063) and Guangxi Natural Science Foundation (No.2014GXNSFDA118024).

\section{Disclosure Statement}

This paper has not been published elsewhere in whole or in part. All authors have read and approved to submit it to your journal. There are no conflicts of interest of any authors in relation to the submission.

\section{References}

1 Hayat SA, Patel B, Khattar RS, Malik RA: Diabetic cardiomyopathy: mechanisms, diagnosis and treatment. ClinSci (Lond) 2004;107:539-557.

$\checkmark 2$ Hinkel R, Howe A, Renner S, Ng J, Lee S, Klett K, Kaczmarek V, Moretti A, Lauqwitz KL, Skroblin P, Mayr M, Milting H, Dendorfer A, Reichart B, Wolf E, Kupatt C: Diabetes mellitus-induced microvascular destabilization in the myocardium. J Am Coll Cardiol 2017;69:131-143.

3 Boodhwani M, Sodha NR, Mieno S, Xu SH, Feng J, Ramlawi B, Clements RT, Sellke FW: Functional, cellular, and molecular characterization of the angiogenic response to chronic myocardial ischemia in diabetes. Circulation 2007;116:131-137. 


\section{Cellular Physiology Cell Physiol Biochem 2018;46:2325-2334 \begin{tabular}{l|l} 
DOI: 10.1159/000489622 & O 2018 The Author(s). Published by S. Karger AG, Basel \\
www.karger.com/cpb
\end{tabular}}

Gui et al.: NRG-1 Promotes Myocardial Angiogenesis in DCM

4 Chou E, Suzuma I, Way KJ, Opland D, Clermont AC, Naruse K, Suzuma K, Bowling NL, Vlahos CJ, Aiello LP, King GL: Decreased cardiac expression of vascular endothelial growth factor and its receptors in insulinresistant and diabetic States: a possible explanation for impaired collateral formation in cardiac tissue. Circulation 2002;105:373-379.

5 Yoon YS, Uchida S, Masuo O, Cejna M, Park JS, Gwon HC, Kirchmair R, Bahlman F, Walter D, Curry C, Hanley A, Isner JM, Losordo DW: Progressive attenuation of myocardial vascular endothelial growth factor expression is a seminal event in diabetic cardiomyopathy: restoration of microvascular homeostasis and recovery of cardiac function in diabetic cardiomyopathy after replenishment of local vascular endothelial growth factor. Circulation 2005;111:2073-2085.

6 Chen JX, Stinnett A: Disruption of Ang-1/Tie-2 signaling contributes to the impaired myocardial vascular maturation and angiogenesis in type II diabetic mice. Arterioscler Thromb Vasc Biol 2008;28:1606-1613.

7 Lemmens K, Segers VF, Demolder M, De Keulenaer GW: Role of neuregulin-1/ErbB2 signaling in endothelium-cardiomyocyte crosstalk. J BiolChem 2006;281:19469-19477.

-8 Odiete 0, Hill MF, Sawyer DB: Neuregulin in cardiovascular development and disease. Circ Res 2012;111:1376-1385.

-9 Russell KS, Stem DF, Polverini PJ, Bender JR: Neuregulin activation of ErbB receptors in vascular endothelium leads to angiogenesis. Am J Physiol 1999;277:H2205-2211.

10 Hedhli N, Dobrucki LW, Kalinowski A, Zhuang ZW, Wu X, Russell RR, Sinusas AJ, Russell KS: Endothelialderived neuregulin is an important mediator of ischaemia-induced angiogenesis and arteriogenesis. Cardiovasc Res 2012;93:516-524.

11 Gui C, Zhu L, Hu M, Lei L, Long Q: Neuregulin-1/ErbB signaling is impaired in the rat model of diabetic cardiomyopathy. Cardiovasc Pathol 2012;21:414-420.

12 Zeng Z, Gui C, Nong Q, Du F, Zhu L: Serum neuregulin-1 $\beta$ levels are positively correlated with VEGF and Angiopoietin-1 levels in patients with diabetes and unstable angina pectoris. Int J Cardiol 2013;168:30773079.

13 Harasiuk D, Baranowski M, Zabielski P, Chabowski A, Gorski J: Liver X Receptor Agonist T0901317 Prevents Diacylglycerols Accumulation in the Heart of Streptozotocin-Diabetic Rats. Cell Physiol Biochem 2016;39:350-359.

14 Boodhwani M, Sodha NR, Mieno S, Ramlawi B, Xu SH, Feng J, Clements RT, Ruel M, Sellke FW: Insulin treatment enhances the myocardial angiogenic response in diabetes. J Thorac Cardiovasc Surg 2007; 134:1453-1460.

15 Hedhli N, Huang Q Kalinowski A, Palmeri M, Hu X, Russell RR, Kussell KS: Endothelium-derived neuregulin protects the heart against ischemic injury. Circulation 2011;123:2254-2262.

-16 Odiete O, Konik EA, Sawyer DB, Hill MF: Type 1 diabetes mellitus abrogates compensatory augmentation of myocardial neuregulin-1 $\beta /$ ErbB in response to myocardial infarction resulting in worsening heart failure. Cardiovasc Diabetol 2013;Doi: 10.1186/1475-2840-12-52.

17 Liu X, Gu X, Li Z, Li X, Li H, Chang J, Chen P, Jin J, Xi B, Chen D, Lai D, Graham RM, Zhou M: Neuregulin-1/ erbB-activation improves cardiac function and survival in models of ischemic, dilated, and viral cardiomyopathy. J Am Coll Cardiol 2006;48:1438-1447.

18 Galindo CL, Kasasbeh E, Murphy A, Ryzhov S, Lenihan S, Ahmad FA, Williams P, Nunnally A, Adcock J, Song Y, Harrell FE, Tran TL, Sawyer DB, Cleator JH: Anti-remodeling and anti-fibrotic effects of the neuregulin-1 $\beta$ glial growth factor 2 in a large animal model of heart failure. J Am Heart Assoc 2014;3:e000773.

19 Bersell K, Arab S, Haring B, Kühn B: Neuregulin1/ErbB4 signaling induces cardiomyocyte proliferation and repair of heart injury. Cell 2009;138:257-270.

20 Sawyer DB, Zuppinger C, Miller TA, Eppenberger HM, Suter TM: Modulation of anthracycline-induced myofibrillar disarray in ratventricular myocytes by neuregulin-1beta and anti-erbb2: potentialmechanism for trastuzumab-induced cardiotoxicity. Circulation 2002;105:1551-1554.

-21 Grazette LP, Boecker W, Matsui T, Semiqran M, Force TL, Hajjar RJ, Rosenzweig A: Inhibition of ErbB2 causes mitochondrial dysfunction in cardiomyocytes: implications for herceptin-induced cardiomyopathy. J Am Coll Cardiol 2004;44:2231-2238.

22 Caillaud K, Boisseau N, Ennequin G, Chavanelle V, Etienne M, Li X, Denis P, Dardevet D, Lacampaqne A, Sirvent P: Neuregulin 1 improves glucose tolerance in adult and old rats. Diabetes Metab 2016;42:96-104.

23 Brero A, Ramella R, Fitou A, Dati C, Alloatti G, Gallo MP, Levi R: Neuregulin-1beta1 rapidly modulates nitric oxide synthesis and calcium handling in rat cardiomyocytes. Cardiovasc Res 2010;88:443-452. 


\section{Cellular Physiology Cell Physiol Biochem 2018;46:2325-2334 \begin{tabular}{ll|l} 
DOI: 10.1159/000489622 & O 2018 The Author(s). Published by S. Karger AG, Basel \\
www.karger.com/cpb
\end{tabular}}

Gui et al.: NRG-1 Promotes Myocardial Angiogenesis in DCM

24 Sheikh AQ, Kuesel C, Taghian T, Hurley JR, Huang W, Wang Y, Hinton RB, Narmoneva DA: Angiogenic microenvironment augments impaired endothelial responses under diabetic conditions. Am J Physiol Cell Physiol 2014;306:C768-778.

25 Loomans CJ, de Koning EJ, Staal FJ, Rookmaaker MB, Verseyden C, de Boer HC, Verhaar MC, Braam B, Rabelink TJ, van Zonneveld AJ: Endothelial progenitor cell dysfunction: a novel concept in the pathogenesis of vascular complications of type 1 diabetes. Diabetes 2004;53:195-199.

-26 Berezin AE: Endothelial progenitor cells dysfunction and impaired tissue reparation: The missed link indiabetes mellitus development. Diabetes Metab Syndr 2017;11:215-220.

-27 Bagheri-Yarmand R, Vadlamudi RK, Wang RA, Mendelsohn J, Kumar R: Vascular endothelial growth factor upregulation via p21-activated kinase-1 signaling regulates heregulin-beta1-mediated angiogenesis. J Biol Chem 2000;275:39451-39457.

-28 Safa RN, Peng XY, Pentassuglia L, Lim CC, Lamparter M, Silverstein C, Walker J, Chen B, Geisberg C, Hatzopoulos AK, Sawyer DB: Neuregulin-1beta regulation of embryonic endothelial progenitor cell survival. Am J Physiol Heart Circ Physiol 2011;300:H1311-1319.

29 Lok J, Sardi SP, Guo S, Besancon E, Ha DM, Rosell A, Kim WJ, Corfas G, Lo EH: Neuregulin-1 signaling in brain endothelial cells. J Cereb Blood Flow Metab 2009;29:39-43.

30 Giacco F, Brownlee M: Oxidative Stress and Diabetic Complications. Circ Res 2010;107:1058-1070.

31 Wilson AJ, Gill EK, Abudalo RA, Edgar KS, Watson CJ, Grieve DJ: Reactive oxygen species signalling in the diabetic heart: emerging prospect for therapeutic targeting. Heart 2018;104:293-299.

32 Xu M, Wu X, Jie B, Zhang X, Zhang J, Xin Y, Guo Y: Neuregulin-1 protects myocardial cells against H2O2 -induced apoptosis by regulating endoplasmic reticulum stress. Cell Biochem Funct 2014;32:464-469.

-33 Shin HS, Lee HJ, Nishida M, Lee MS, Tamura R, Yamashita S: Betacellulin and amphiregulin induce upregulation of cyclin D1 and DNA synthesis activity through differential signaling pathways in vascular smooth muscle cells. Circ Res 2003;93:302-310.

34 Kim HS, Shin HS, Kwak HJ, Cho CH, Lee CO, Koh GY: Betacellulin induces angiogenesis through activation of mitogen-activated proteinkinase and phosphatidylinositol 3'-kinase in endothelial cell. FASEB J 2003;17:318320.

35 Karamysheva AF: Mechanisms of Angiogenesis. Biochemistry 2008;73:751-762.

-36 Iivanainen E, Paatero I, Heikkinen SM, Junttila TT, Cao R, Kint P, Jaakkola PM, Cao Y, Elenius K: Intra- and extracellular signaling by endothelial neuregulin-1. Exp Cell Res 2007;313:2896-2909.

37 Nakaoka Y, Nishida K, Narimatsu M, Kamiya A, Minami T, Sawa H, Okawa K, Fujio Y, Koyama T, Maeda M, Sone M, Yamasaki S, Arai Y, Koh GY, Kodama T, Hirota H, Otsu K, Hirano T, Mochizuki N: Gab family proteins are essential for postnatal maintenance of cardiac function via neuregulin-1/ErbB signaling. J Clin Invest 2007;17:1771-1781. 